\title{
Free Vibration Response of Four-Parameter Functionally Graded Thick Spherical Shell Formulation on Higher-Order Shear Deformation Theory
}

\author{
Raparthi Srilakshmi, Ch. Ratnam, Chandra Mouli Badiganti
}

\begin{abstract}
This paper emphasizes on the free vibration (FV) responses of functionally graded thick spherical shell in rectangular form using traditional mathematical formulation on finite element method and governed by Higher order shear deformation theory (HOSDT). A functionally graded spherical shell made up of metal-rich on the top surface and in contrast, base surface of the model is ceramic-rich. The FG volume fraction of four-parameter power-law material constituents assumed in the thickness direction. To highlight the potential for the current method, convergence studies, and validation tests performed to establish the stability and accuracy attained by the current approach. The parametric studies presented to scrutinize the influence of choice of four parameters employed through power-law distribution. The eminence effect of spherical shell geometrical properties, and different types of support conditions, skew angle on the FV behavior of non-dimensional frequency responses examined in detail.
\end{abstract}

Keyword: Free vibration, HSDT, Finite element method, Spherical shell.

\section{INTRODUCTION}

The continuous evaluation of develop materials and to optimize the structural design have received significant attention in many engineering areas and manufacturing industries. FGMs are a structurally advanced new class of composites. The concept originated in the 1980s in Japan. FGMs continuous gradation behavior of material composition (metal and ceramic) and microstructure. FGMs preferred in many sectors because of their mechanical and heat-shielding characteristics while maintaining structural integrity and reducing stress concentrations. Many research works contributed to bending and buckling analysis. The vibration behavior of shells plays a crucial role in design aerospace equipment, spacecraft, rockets, missiles, containers, hydraulic structures, submarines, ships, storage tanks.

Revised Manuscript Received on February 05, 2020.

* Correspondence Author

Raparthi Srilakshmi*, Department of Mechanical Engineering, Andhra University, Visakhapatnam, India. Email: srilakshmi053@gmail.com

Ch.Ratnam, Department of Mechanical Engineering, Andhra University, Visakhapatnam, India. Email: chratnam@gmail.com

Chandra Mouli Badiganti, Department of Mechanical Engineering, RISE Group of Institutions, Ongole, India. Email: badiganti1@gmail.com

(C) The Authors. Published by Blue Eyes Intelligence Engineering and Sciences Publication (BEIESP). This is an open access article under the CC BY-NC-ND license (http://creativecommons.org/licenses/by-nc-nd/4.0/)
Revised Manuscript Received on February 05, 2020.

* Correspondence Author

Loy et al. [1] examined the vibration of cylindrical with FGMs constituents with- general boundary conditions. The analysis considered based-on Love's Shell theory and Rayleigh-Ritz's method. A similar approach followed Pradhan et al. [2] studied FG Cylindrical Shells under different boundary conditions formulation on classical plate theory. Reddy [3] presented an analysis of Functionally graded plates. Ng et al. [4] introduced the dynamic stability analysis of FG shells under harmonic axial loading and Bolotin's approximation. K. M. Liew et al. [5] studied a three-dimensional vibration analysis of spherical shells panel subjected to various boundary conditions employing the P-Ritz method.

J.N. Reddy and Z.Q. Cheng [6] studied a spherical shallow shell in polygonal planform resting on a Winkler Pasternak elastic foundation. $\mathrm{Hu}$ et al. [7] studied the natural frequencies of rotating twisted and open conical shells. E. Artioli and Viola [8] presented the FV analysis of spherical caps using the Generalized Differential Quadrature (GDQ) procedure and the FEM approach. Arciniega and J.N. Reddy [9] described, Nonlinear analysis for functionally graded shells. The formulation is on the first-order shear deformation theory (FSDT) with seven independent parameters.

Zhao et al. [10] analyzed the FV of functionally graded shells using the element-free KP-Ritz method.F. Tornabene and E. Viola [11], [12] investigated the dynamic behavior of vibration analysis of hemispherical domes and spherical shell panels using FSDT. Later on, the same authors developed a 2-D solution for free vibrations of parabolic shells using a GDQ, and the FSDT is used to analyze the above moderately thick structural elements. Numerical solutions with the ones obtained using commercial programs such as Abaqus, Ansys, Femap/Nastran, Straus, Pro/Mechanica used. F. Tornabene [13] investigated based on the FSDT. Dynamic behavior of moderately thick FG conical, cylindrical shells, and annular plates with two different power-law distributions presented. Tornabene et al. [14]- [16] extended the GDQ procedure for the FV analysis of FG doubly-curved panels and shells of revolution with classical boundary conditions.

M.H.yas and B. Sobhani Aragh [17] studied three-dimensional analysis for the thermoelastic response of functionally graded fiber-reinforced cylindrical panel. 
Amabili and J.N. reddy [18] studied higher-order deformation nonlinear theory for the large amplitude of forced vibration of laminated doubly curved shells. Mohammad Talha and B.N Singh [19] studied static response and FV analysis of FGM plates using higher order shear deformation theory and conjunction with finite element method.

Shen and Z.X. Wang [20] described based on HSDT, comparison studies of two kinds of micromechanics models, namely Voigt's and Mori-Tanaka models for vibration analysis of FG plates. Neves A.M.A et al. [21] presented with FV problems of FG spherical as well as cylindrical shell panels with all edges clamped or simply supported. The analysis is performed by radial basis functions collocation, according to a HSDT that accounts for through-the-thickness deformation. Discretization method-based on the FSDT.

V. R. Kar and S. K. Panda [22]. investigated the vibration and thermal buckling characteristics of FG single/double curved panels under linear and nonlinear behaviors temperatures fields are studied. Kumar et al. [23] developed for $\mathrm{FV}$ analysis of laminated composite skew cylindrical shells. A $\mathrm{C}_{0}$ finite element formulation based on using HSDT.

C. Zhang et al. [24] presented the improved Fourier series method based on Hamilton's principle to investigate the vibration characteristics of circular cylindrical double-shell structures with different boundary conditions. Devesh Punera and Tarun Kant [25] developed FV of FG open cylindrical shells based on several refined higher-order displacement models. Mouli and Ramji Koona [26]-[28] examined the influence of different parameters on the FV behavior of FG Skew shallow curved panels.

In the present work focused on the FV characteristics of FGM rectangular spherical shell. The formulation based on Higher-order deformation theory conjunction with the finite-element method. The comprehensive parametric studies carried out to examine the influence of power-law distribution and Choice of four parameters on material composition in terms of volume fraction constituents. and the significance of Geometric parameters is that the shell aspect ratio, thickness ratio, and curvature ratio. and the impact of different boundary conditions, skew angle, on the non-dimensional frequency responses, are studied.

\section{FGM MATERIAL PROPERTIES AND FOUR-PARAMETER POWER-LAW DISTRIBUTION PARAMETERS}

In this part, the variation of volume fraction through the different values of power-law exponent and choice of distribution parameters with classic, with reference surface to the shell (Symmetric) and without reference surface (asymmetric) volume fraction profiles illustrated. The material properties of the FG spherical shell are assumed to vary throughout the thickness, where $\vartheta_{\mathrm{m}}$ and $\vartheta_{\mathrm{c}}$ are the volume fractions of metal and ceramic. Similarly, in which subscripts $\mathrm{c}$ and $\mathrm{m}$ represent the ceramic and metal constituents, as in (1a), (1b), and (1c) mechanical properties are Young's modulus $\mathrm{E}(\xi)$, density $(\xi)$, and poisons ratio(v) vary continuously to achieve smooth gradation of material phase through the spatial direction $(\xi)$ expressed in the form of a linear combination. The sum of the volume fraction of the constituent materials should be equal to one, as in (2).

$$
\begin{gathered}
\mathrm{E}(\xi)=\left(E_{c}-E_{m}\right) \vartheta_{c}+\vartheta_{m} \\
\rho(\xi)=\left(\rho_{c}-\rho_{m}\right) \vartheta_{c}+\rho_{m} \\
\nu(\xi)=\left(\vartheta_{c}-\vartheta_{m}\right) \vartheta_{c}+\vartheta_{m} \\
\vartheta_{c}+\vartheta_{m}=1
\end{gathered}
$$

According to the following power-law function as in (3) Where $\varphi$ is the power-law exponent varying as $0 \leq \varphi \leq \infty$, and the distribution parameters $\mathrm{u}, \mathrm{v}, \mathrm{w}$ and different values of power law exponent generates material variation profiles through the thickness direction in terms of volume fraction. For example, FG constituents of the shell thickness demonstrated through four parameter power law distribution. the material distribution in the FGM shell is continuously varied, such that the bottom surface $(-\mathrm{h} / 2)$ of the structure is pure ceramic. In contrast, the top surface $(+\mathrm{h} / 2)$ pure metal, by setting $\mathrm{u}=1$ and $\mathrm{v}=0, \mathrm{w}=0$, as in (3).

$$
\operatorname{FGM}_{(\mathrm{u} / \mathrm{v} / \mathrm{w} / \varphi)}: \vartheta_{C}=\left(1-u\left(\frac{1}{2}+\frac{\xi}{h}\right)+\mathrm{v}\left(\frac{1}{2}+\frac{\xi}{h}\right)^{w}\right)^{\varphi}
$$

Fig.1 shows the classic volume fraction profiles, power-law distributions are considered for the volume fraction of the ceramic. The first distribution FGM $(u=1, v=0 / w=1 / \varphi)$, the material composition is continuously varied, such that the bottom surface of $\xi / \mathrm{h}=-0.5$ of the shell's ceramic-rich. In contrast, the top surface $(\xi / \mathrm{h}=0.5)$ is metal-rich.

Fig. 2 shows the significance of the various power-law distribution of patterns by modifying the parameters $\mathrm{u}, \mathrm{v}, \mathrm{w}$, and $\varphi$ for the given constituents of volume fraction.by varying the power law exponent $(\varphi)$ and symmetric respect to the reference surface $(\xi / \mathrm{h}=0)$ of the shell.by setting the first four parameter power law distribution FGM $(\mathrm{u}=1, \mathrm{v}=1$ and $\mathrm{w}=3)$.

Fig.3 illustrate profiles are not symmetric with respect to the reference surface $(\xi / \mathrm{h}=0)$ of the shell. asymmetric profiles obtained by setting FGM $(u=1, v=1, w=5 / \varphi)$.

Figs.4-6. depicts varying the parameters $u, v, w$. These material profiles characterized by the fact that one of the shells surfaces the top or bottom surface presents a composed of two constituents. For example, by setting the values as in (3) and the power-law distribution is FGM $(u=1, v=0.4, w=3)$ and different quantity values of the power-law exponent. From the design point of view, it is essential to know the top surface is of the shell $\xi / \mathrm{h}=0.5$ is ceramic or metal. If the bottom surface $\xi / \mathrm{h}=-0.5$ is metal or ceramic- rich. One of these surfaces presents a mixture of two constituents. It is worth noting that types four-parameter power-law distributions as enunciated by F. Tornabene [13]-[16], and the author provided more detailed descriptions about the material variation profile of FGMs.

The primary purpose of this section The Voigt's rule is employed to estimate the ceramic volume fraction. The four-parameter power-law distribution affects the desired volume fraction of the material on the top and bottom surface of the structure. 
Thus, FGM material properties of layers change continuously and smoothly in the thickness direction. The influence of the choice of four material parameters $\mathrm{u}, \mathrm{v}, \mathrm{w}, \varphi$, and to study the variation of the volume fraction of the material constituents and effects of various forms of classic, symmetric and asymmetric material pattern profiles which change the mechanical behavior of a structure.

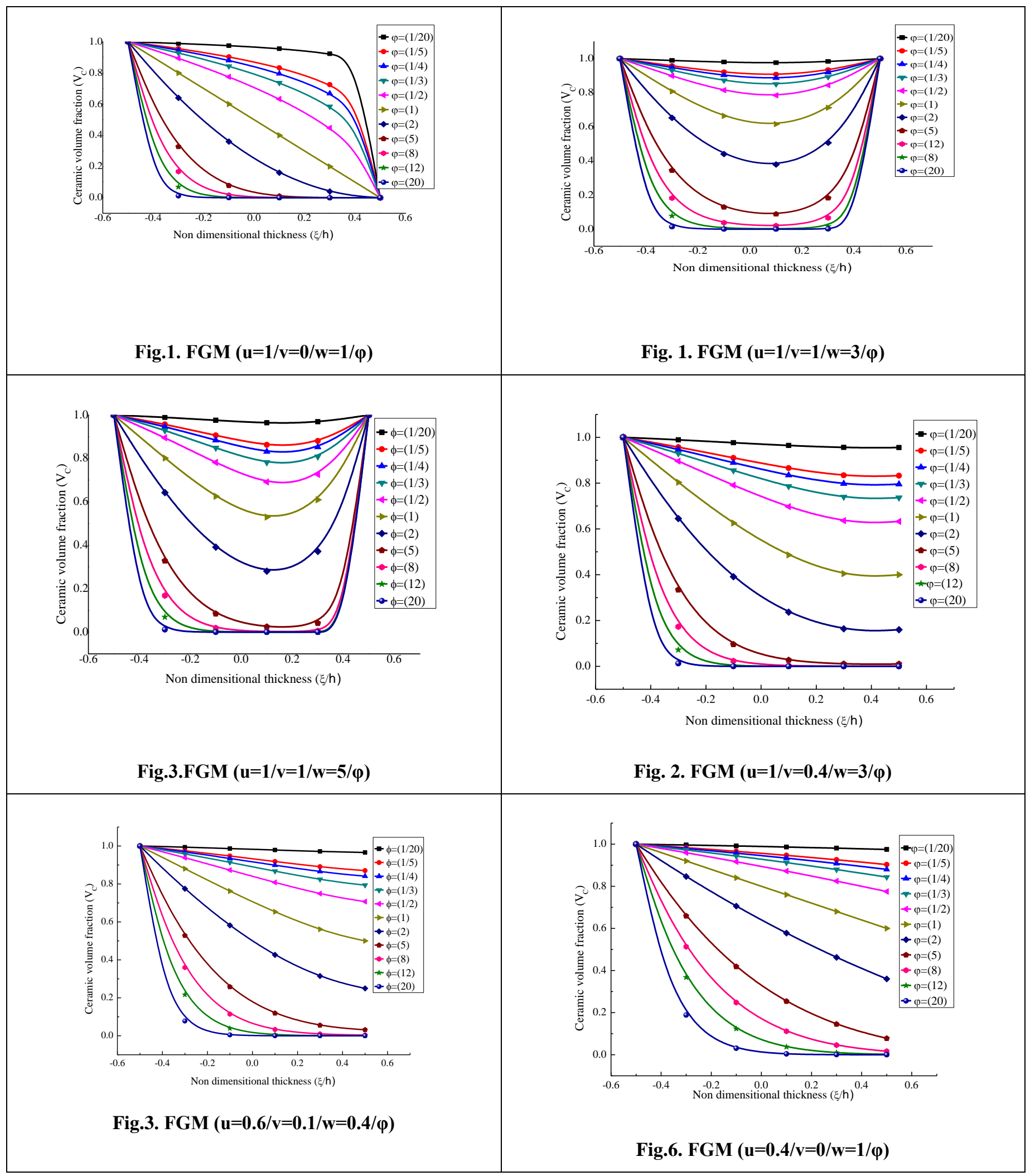

Fig. 1-6. Variation of ceramic volume fraction $\left(\boldsymbol{\vartheta}_{c}\right)$ through the FG structure thickness $(\xi)$ for different values of three parameters $u, v, w$, and $\varphi$

\section{FRAMEWORK OF GOVERNING EQUATIONS}

3.1 Kinematic Paradigm and numerical procedure

Retrieval Number: C4812029320/2020@BEIESP

DOI: 10.35940/ijeat.C4812.029320

Journal Website: www.ijeat.org
Published By:

466 Blue Eyes Intelligence Engineering \& Sciences Publication 
In this framework, the formulation procedure for governing equations obtained by a general shallow curved spherical shell is represented by a, b, and thickness $\mathrm{h}$, in $\mathrm{x}$, y directions, as shown in Fig.7. Here, Rx and Ry are the radii of curvature along $\mathrm{x}$ and $\mathrm{y}$ direction, respectively. The TSDT mid-plane kinematics model utilized to define the global displacements $(\chi, \lambda, \psi$,$) at any point in terms of mid-plane displacements \left(\chi_{0}\right.$, $\left.\lambda_{0}, \psi_{0}\right)$,

rotations $\left(\theta_{x}, \theta_{y}\right)$ and higher-order $\left(\chi_{0}^{*}, \lambda_{0}^{*}, \theta_{x}^{*}, \theta_{y}^{*}\right)$ terms, as per Pandya \& Kant, [30].

$$
\left.\begin{array}{l}
\chi=\chi_{0}+\xi \theta_{x}+\xi^{2} \chi_{0}^{*}+\xi^{3} \theta_{x}^{*} \\
\lambda=\lambda_{0}+\xi \theta_{y}+\xi^{2} \lambda_{0}^{*}+\xi^{3} \theta_{y}^{*} \\
\psi=\psi_{0}
\end{array}\right\}
$$

This kinematic model, (5) can be rewritten in the matrix form as in (5)

$$
\{\delta\}=[F]\left\{\delta_{0}\right\}
$$

where, $\{\delta\}=\left\lfloor\begin{array}{lll}\chi & \lambda & \psi\end{array}\right\rfloor^{T}$ and $\left\{\delta_{0}\right\}=$ $\left\lfloor\begin{array}{lllllllll}\chi_{0} & \lambda_{0} & \psi_{0} & \theta_{x} & \theta_{y} & \chi_{0}^{*} & \lambda_{0}^{*} & \theta_{x}^{*} & \theta_{y}^{*}\end{array}\right\rfloor^{T}$ are the global and mid-plane displacement vectors. $[F]$ contains the thickness coordinate functions, as expressed here in (6)

$$
[F]=\left[\begin{array}{ccccccccc}
1 & 0 & 0 & \xi & 0 & \xi^{2} & 0 & \xi^{3} & 0 \\
0 & 1 & 0 & 0 & \xi & 0 & \xi^{2} & 0 & \xi^{3} \\
0 & 0 & 1 & 0 & 0 & 0 & 0 & 0 & 0
\end{array}\right]
$$

The shallow curved shell is shown in Fig.7(ii) with sides $a$ and $b$. To constraint the oblique edges, the local displacement vector is required to transform to global via transformation matrix [ $F$ and expressed in cosine $(l)$ and sine ( $m$ ) terms. The displacement transformation revealed as

$$
\left\{\begin{array}{l}
\chi_{0} \\
\lambda_{0} \\
\psi_{0} \\
\theta_{x} \\
\theta_{y} \\
\chi_{0}^{*} \\
\lambda_{0}^{*} \\
\theta_{x}^{*} \\
\theta_{y}^{*}
\end{array}\right\}=\left[\begin{array}{ccccccccc}
l & -m & 0 & 0 & 0 & 0 & 0 & 0 & 0 \\
m & l & 0 & 0 & 0 & 0 & 0 & 0 & 0 \\
0 & 0 & 1 & 0 & 0 & 0 & 0 & 0 & 0 \\
0 & 0 & 0 & l & -m & 0 & 0 & 0 & 0 \\
0 & 0 & 0 & m & l & 0 & 0 & 0 & 0 \\
0 & 0 & 0 & 0 & 0 & l & -m & 0 & 0 \\
0 & 0 & 0 & 0 & 0 & m & l & 0 & 0 \\
0 & 0 & 0 & 0 & 0 & 0 & 0 & l & -m \\
0 & 0 & 0 & 0 & 0 & 0 & 0 & m & l
\end{array}\right]\left\{\begin{array}{c}
\chi_{0}^{\prime} \\
\lambda_{0}^{\prime} \\
\psi_{0}^{\prime} \\
\theta_{x}^{\prime} \\
\theta_{y}^{\prime} \\
\chi_{0}^{* \prime} \\
\lambda_{0}^{* \prime} \\
\theta_{x}^{* \prime} \\
\theta_{y}^{* \prime}
\end{array}\right\}
$$

(7) can also be written as

$$
\left\{\Omega_{0}\right\}=[F]\left\{\Omega_{0}^{\prime}\right\}
$$

where, $\left\{\Omega_{0}^{\prime}\right\}$ is the displacement field defined in the local coordinates.

The strain-displacement equation for any general shallow thick plate can be written as (Kar and Panda, [22])

$$
\left\{\begin{array}{l}
\varepsilon_{x x} \\
\varepsilon_{y y} \\
\gamma_{x y} \\
\gamma_{x z} \\
\gamma_{y z}
\end{array}\right\}=\left\{\begin{array}{l}
\frac{\partial \chi}{\partial x}+\frac{\psi}{R_{x}} \\
\frac{\partial \lambda}{\partial y}+\frac{\psi}{R_{y}} \\
\frac{\partial \chi}{\partial y}+\frac{\partial \lambda}{\partial x} \\
\frac{\partial \chi}{\partial z}+\frac{\partial \psi}{\partial x}-\frac{\chi}{R_{x}} \\
\frac{\partial \lambda}{\partial z}+\frac{\partial \psi}{\partial y}-\frac{\lambda}{R_{y}}
\end{array}\right\}
$$

By imposing the displacement terms (4) in the strain-displacement as in (9), the global strain tensor can be modified as

$$
\begin{aligned}
& \left\{\begin{array}{l}
\varepsilon_{x x} \\
\varepsilon_{y y} \\
\gamma_{x y} \\
\gamma_{x z} \\
\gamma_{y z}
\end{array}\right\}=\left\{\begin{array}{l}
\varepsilon_{x}{ }^{0} \\
\varepsilon_{y}{ }^{0} \\
\varepsilon_{x y}{ }^{0} \\
\varepsilon_{x z}{ }^{0} \\
\varepsilon_{y z}{ }^{0}
\end{array}\right\}+\xi\left\{\begin{array}{l}
k_{x}{ }^{1} \\
k_{y}{ }^{1} \\
k_{x y}{ }^{1} \\
k_{x z}{ }^{1} \\
k_{y z}{ }^{1}
\end{array}\right\}+\xi^{2}\left\{\begin{array}{l}
k_{x}{ }^{2} \\
k_{y}{ }^{2} \\
k_{x y}{ }^{2} \\
k_{x z}{ }^{2} \\
k_{y z}{ }^{2}
\end{array}\right\}+\xi^{3}\left\{\begin{array}{l}
k_{x}{ }^{3} \\
k_{y}{ }^{3} \\
k_{x y}{ }^{3} \\
k_{x z}{ }^{3} \\
k_{y z}{ }^{3}
\end{array}\right\} \\
& \varepsilon=\varepsilon^{0}+\xi k^{1}+\xi^{2} k^{2}+\xi^{3} k^{3}
\end{aligned}
$$

where, $\varepsilon^{0}, k^{1}, k^{2}$ and $k^{3}$ are the mid-plane strain, curvature and higher-order terms respectively as per Kar and Panda [22].

(11) can be again rearranged as

$\{\varepsilon\}=[F]\{\bar{\varepsilon}\}$

where, $\{\bar{\varepsilon}\}=\left\lfloor\begin{array}{llll}\varepsilon^{0} & k^{1} & k^{2} & k^{3}\end{array}\right\rfloor^{T}$ is the mid-plane strain, and $F=\left[\begin{array}{llll}I & \xi I & \xi^{2} I & \xi^{3} I\end{array}\right]$ is the thickness-coordinate matrix, in which $I$ is the unit matrix of size $5 \times 5$.

\subsection{Finite Element Approximations}

In this section, the present FG shallow spherical panel is discretized based on a finite element modeling using a nine-node isoperimetric element with eighty-one degrees-of the displacements defined in the mid-plane can in a nodal form as

$$
\left\{\Omega_{0}\right\}=\sum_{i=1}^{9} N_{i}\left\{\Omega_{0_{i}}\right\}
$$

where, $\left\{\Omega_{0_{i}}\right\}$ and $N_{i}$ are the nodal displacement vector and the approximation function at ith node (Cook et al. [29]). Now, the total and geometric mid-plane strain vectors can be expressed as in (13) as

$$
\{\bar{\varepsilon}\}=[B]\left\{\Omega_{0_{i}}\right\} \text { and }\left\{\bar{\varepsilon}_{G}\right\}=\left[B_{G}\right]\left\{\Omega_{0_{i}}\right\}
$$

where, $[B]$ and $\left[B_{G}\right]$ are the differential operators of the total and geometrical mid-plane strains respectively. By imposing (12)-(15) in the above governing equation, the equilibrium equation of the vibrated FG shallow shell panel is achieved and expressed in global form, as

$$
\left([K]-\left[K_{G}\right]-\omega^{2}[M]\right) \Delta=0
$$

where, $[M]=[N]^{T}[m][N]$ is the global mass matrix,

$[K]=[B]^{T}[D][B]$ is the global stiffness matrix,

$\left[K_{G}\right]=\left[B_{G}\right]^{T}\left[D_{G}\right]\left[B_{G}\right]$ is the geometric stiffness matrix and $\omega$ and $\Delta$ are the natural frequency and eigenvalue type the corresponding eigen vectors. 


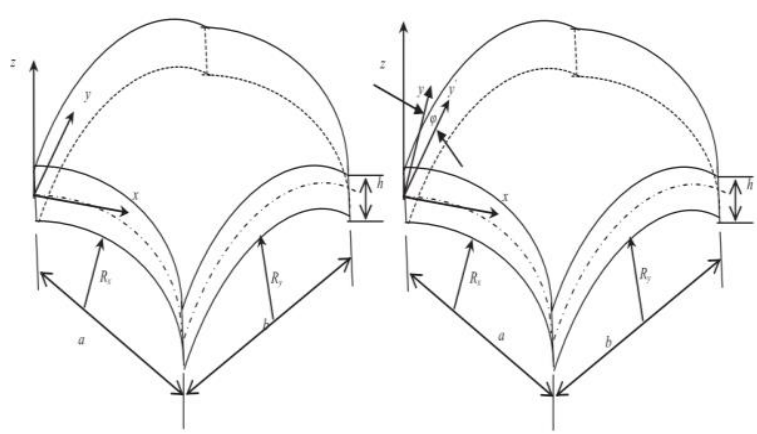

Fig. 7.(i) spherical curved shell form (ii) spherical curved shell skew form

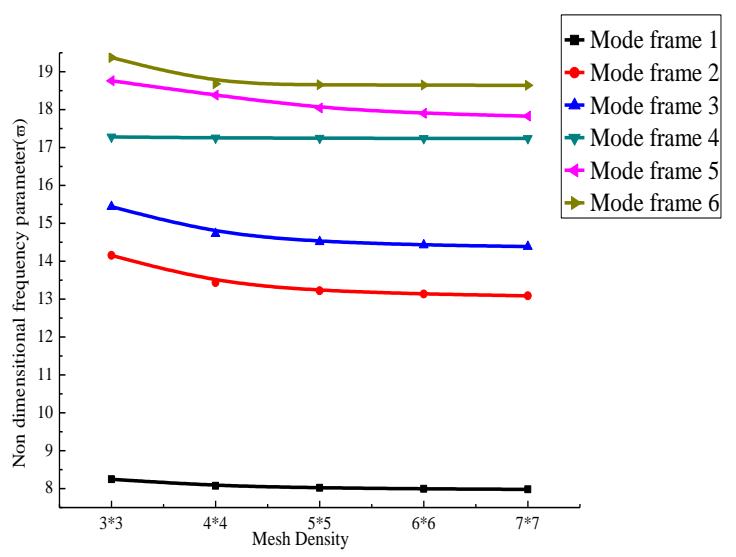

Fig. 8. Dimensionless frequency parameter SSSS

\section{RESULTS AND DISCUSSION}

The theoretical model is developed in the present study using the HSDT and FG spherical shells under FV analysis. Material Properties play a vital role in determining the response of natural frequencies of the FG Spherical shell. Table I. shows the material properties of FGM constituents. It should be that the

non-dimensional excitation frequency parameter defined. The results presented in Table II-XII are shown based on the dimensionless natural frequency, according to, as in (16).

$$
\left(\bar{\omega}=\omega\left(a^{2} / h\right) \sqrt{\rho_{c} / E_{c}}\right)
$$

Table I. Material properties of Strain less steel and Silicon nitrate[10]

\begin{tabular}{|l|l|l|l|}
\hline Metal: & SUS304 & Ceramic: & $\mathrm{Si}_{3} \mathrm{~N}_{4}$ \\
\hline E(Gpa): & $207.78 \times 10^{9}$ & $\mathrm{E}(\mathrm{Gpa}):$ & $322.27 \times 10^{9}$ \\
\hline$\mu:$ & 0.3177 & $\mu:$ & 0.24 \\
\hline
\end{tabular}

Table- II. shows the comparison of Non-dimensional frequency parameter for FG spherical (Aluminum (Al) and Silicon Carbide (Sic)), shell panels with different Thickness (a/h) ratios.

\begin{tabular}{|c|c|c|c|c|c|c|c|c|c|c|c|}
\hline \multicolumn{12}{|c|}{ Skew angle $(\alpha)$} \\
\hline \multicolumn{4}{|c|}{$0^{0}$} & \multicolumn{2}{|c|}{$15^{0}$} & \multicolumn{2}{|c|}{$30^{0}$} & \multicolumn{2}{|c|}{$45^{0}$} & \multicolumn{2}{|c|}{$60^{\circ}$} \\
\hline $\mathrm{a} / \mathrm{h}$ & Mode & $\begin{array}{l}\text { Mouli } \\
\text { et.al } \\
{[26]}\end{array}$ & Present & $\begin{array}{l}\text { Mouli } \\
\text { et.al } \\
{[26]}\end{array}$ & Present & $\begin{array}{l}\text { Mouli } \\
\text { et.al } \\
\text { [26] }\end{array}$ & Present & $\begin{array}{l}\text { Mouli } \\
\text { et.al } \\
{[26]}\end{array}$ & Present & $\begin{array}{l}\text { Mouli } \\
\text { et.al [26] }\end{array}$ & Present \\
\hline
\end{tabular}
determine the uniformesh frequencies converge and a suitable number of homogeneous layers to represent the FG Spherical panel. In the following, as a first part, to examine the present solution, the convergence properties of the fundamental frequency SUS304/ Si3N4 for spherical shells in the rectangular form with simply supported conditions considered. The results are In Fig.8. The discussion is made only on the present numerical results for the uniform mesh size of $6 \times 6$. Therefore, based on the above analysis, the subsequent $6 \times 6$.

\subsection{Comparison Study}

Table II. shows the frequencies of the first five modes for a Simply- supported, spherical shell $(\mathrm{Rx}=\mathrm{Ry}=\mathrm{R})$ in rectangular form. Composed of Aluminum (Al) and Silicon Carbide (Sic) for four different values of the thickness ratios $(\mathrm{a} / \mathrm{h}=5,20,50$, and 200). The power-law distribution parameters FGM $(u=1, v=0, \quad w=2, \varphi=2)$, Geometrical parameters $\mathrm{R} / \mathrm{a}=5, \mathrm{a} / \mathrm{b}=1$ and five skew angle $0^{\circ}, 15^{\circ}, 30^{\circ}$, $45^{\circ}, 60^{0}$ are considered. The results of good agreement with the HSDT accurate solutions given by Mouli et al. [26] The ximum difference between them is $1.82 \%$ and by using the computer code in the MATLAB environment, which is developed based on HSDT formulated by the finite the effectiveness of the present developed model.

\subsection{Numerical examples and results}

In this section, the FV behavior of the FG spherical shell, which is composed of two constituents ceramic- rich (silicon nitride Si3N4), and metal-rich (stainless steel SUS304), and the material properties same for all numerical examples, and the Poisson's ratios $(\mu)$ of both materials 0.3 chosen. The sults were analyzed using four-parameter power-law The material distribution applied through-thickness $(\xi)$ direction. Power-law Variation and choice of power-law material distribution parameters (u, v, $w)$. Examine the influence of the vibration behavior of the FG (he effects of the material composition in terms of volume fraction. Four power-law distribution parameters FGM (u, v, w, $\varphi$ ) as in (3) and the significance of geometrical ratios, and skew angle on the non-dimensional frequency responses are FGM structure presented. 
Free Vibration Response of Four-Parameter Functionally Graded Thick Spherical Shell Formulation on Higher-Order Shear Deformation Theory

\begin{tabular}{|c|c|c|c|c|c|c|c|c|c|c|c|}
\hline \multirow[t]{5}{*}{5} & 1 & 3.4100 & 3.4723 & 6.8281 & 6.7500 & 6.8290 & 6.7509 & 7.4322 & 7.5446 & 7.4328 & 7.5452 \\
\hline & 2 & 3.6408 & 3.7063 & 7.0037 & 6.9254 & 7.0591 & 6.9807 & 7.3561 & 7.4637 & 8.2882 & 8.4083 \\
\hline & 3 & 4.4156 & 4.4915 & 7.6278 & 7.5454 & 7.7858 & 7.7095 & 8.0807 & 8.1815 & 10.1929 & 10.3287 \\
\hline & 4 & 6.1069 & 6.2049 & 8.9230 & 8.8249 & 9.3418 & 9.2572 & 9.9786 & 10.0878 & 11.8894 & 11.7596 \\
\hline & 5 & 10.0314 & 10.1768 & 11.6240 & 11.4933 & 12.7402 & 12.6242 & 14.4919 & 14.5521 & 14.7162 & 14.6343 \\
\hline \multirow[t]{5}{*}{20} & 1 & 4.6859 & 4.7087 & 9.8392 & 9.8906 & 9.8399 & 9.8913 & 15.1368 & 15.2157 & 19.2254 & 19.3233 \\
\hline & 2 & 5.2709 & 5.2962 & 10.1067 & 10.1585 & 11.6470 & 11.7064 & 15.8461 & 15.9268 & 20.6338 & 20.7377 \\
\hline & 3 & 6.6948 & 6.7273 & 11.8048 & 11.8646 & 15.7501 & 15.8288 & 18.1545 & 18.2445 & 25.3188 & 25.4429 \\
\hline & 4 & 9.5462 & 9.5934 & 15.6993 & 15.7782 & 23.3829 & 23.4959 & 23.9133 & 24.0316 & 32.7678 & 32.9211 \\
\hline & 5 & 17.1977 & 17.2814 & 26.1756 & 26.3045 & 37.2351 & 37.4083 & 44.4248 & 44.6480 & 47.0353 & 46.9039 \\
\hline \multirow[t]{5}{*}{50} & 1 & 7.9556 & 7.9688 & 11.9952 & 12.0188 & 11.9964 & 12.0200 & 16.9843 & 17.0197 & 21.5536 & 21.5990 \\
\hline & 2 & 8.8234 & 8.8384 & 12.8408 & 12.8659 & 15.2141 & 15.2436 & 19.1813 & 19.2201 & 23.5513 & 23.6006 \\
\hline & 3 & 10.0229 & 10.0410 & 14.7504 & 14.7800 & 19.9778 & 20.0184 & 22.5151 & 22.5611 & 29.7915 & 29.8538 \\
\hline & 4 & 12.7876 & 12.8121 & 19.3674 & 19.4070 & 29.6364 & 29.6978 & 29.9588 & 30.0198 & 44.0315 & 44.1225 \\
\hline & 5 & 21.6786 & 21.7218 & 33.2335 & 33.3015 & 51.2778 & 51.3790 & 56.5794 & 56.6961 & 75.5599 & 75.7033 \\
\hline \multirow[t]{5}{*}{200} & 1 & 28.2112 & 28.2218 & 29.7181 & 29.7298 & 29.7252 & 29.7368 & 32.0759 & 32.0892 & 35.0713 & 35.0865 \\
\hline & 2 & 28.7029 & 28.7137 & 30.3673 & 30.3793 & 32.3829 & 32.3963 & 34.6465 & 34.6614 & 36.9586 & 36.9751 \\
\hline & 3 & 29.1911 & 29.2023 & 31.2642 & 31.2769 & 34.8612 & 34.8764 & 36.6680 & 36.6830 & 41.9366 & 41.9563 \\
\hline & 4 & 30.6427 & 30.6547 & 34.2175 & 34.2323 & 42.4027 & 42.4227 & 43.4188 & 43.4394 & 55.7493 & 55.7774 \\
\hline & 5 & 36.8841 & 36.9000 & 47.0289 & 47.0518 & 69.3334 & 69.3690 & 70.5579 & 70.5947 & 101.8152 & 101.8692 \\
\hline
\end{tabular}

\subsubsection{Example}

Table III. shows the effect of general boundary conditions, namely- supported (SSSS), clamped boundary condition (CCCC), and Hinged (HHHH) all sides and FGM Power-law distribution $(\mathrm{u}=1 / \mathrm{v}=1 / \mathrm{w}=2 / \varphi=2)$ and the following geometric values used for the analysis $(\mathrm{a} / \mathrm{h}=10, \mathrm{R} / \mathrm{a}=5)$. The results reveal the SSSS condition exhibit lower frequencies for all six modes compared to other boundary conditions. Clamped boundary conditions would also strengthen for all frequency responses. Consequently, it induces higher frequency responses of vibration of the shell. A similar trend mirrored for all the other cases.

Table-III: Variation of non-dimensional frequency responses With ( $\alpha$ ) for FG spherical shell (SUS304/Si3N4) panel for different boundary conditions.

\begin{tabular}{|l|l|l|l|l|l|l|}
\hline \multicolumn{7}{|c|}{ Skew angle $(\alpha)$} \\
\hline BCC & Mode & $0^{0}$ & $15^{0}$ & $30^{0}$ & $45^{0}$ & $60^{0}$ \\
\hline \multirow{5}{*}{ SSSS } & 1 & 6.6053 & 7.1838 & 9.0387 & 13.0503 & 22.9678 \\
\cline { 2 - 7 } & 2 & 15.1406 & 15.0826 & 17.0006 & 21.9219 & 34.2981 \\
\cline { 2 - 7 } & 3 & 15.1419 & 17.2313 & 22.0854 & 27.0449 & 35.4864 \\
\cline { 2 - 7 } & 4 & 20.5923 & 21.1368 & 23.0593 & 28.4055 & 39.1695 \\
\cline { 2 - 7 } & 5 & 20.5951 & 21.3085 & 23.5884 & 31.0722 & 45.2798 \\
\cline { 2 - 7 } & 6 & 23.0281 & 23.3723 & 25.4397 & 32.1331 & 45.6577 \\
\hline \multirow{5}{*}{ CCCC } & 1 & 11.1883 & 11.7655 & 13.8032 & 18.6021 & 30.6740 \\
\cline { 2 - 7 } & 2 & 20.7881 & 20.6460 & 22.6770 & 28.2155 & 42.2235 \\
\cline { 2 - 7 } & 3 & 20.7881 & 22.9958 & 28.1145 & 37.8034 & 53.7746 \\
\cline { 2 - 7 } & 4 & 29.0141 & 29.4013 & 31.6162 & 38.7717 & 58.9064 \\
\hline & 5 & 34.7061 & 36.2572 & 40.9409 & 46.1865 & 63.2556 \\
\hline \multirow{5}{*}{ HHHH } & 6 & 35.0660 & 37.6715 & 41.5800 & 48.5456 & 66.5826 \\
\hline & 1 & 7.0277 & 7.5702 & 9.3421 & 13.2590 & 23.0909 \\
\cline { 2 - 7 } & 2 & 15.1740 & 15.1275 & 17.0526 & 21.9776 & 34.3717 \\
\cline { 2 - 7 } & 3 & 15.1752 & 17.2516 & 22.1042 & 31.1155 & 45.5663 \\
\cline { 2 - 7 } & 5 & 23.0613 & 23.4081 & 25.4796 & 32.1119 & 55.4464 \\
\cline { 2 - 7 } & 6 & 28.3663 & 29.9099 & 35.1487 & 41.5272 & 56.5141 \\
\hline
\end{tabular}

\subsubsection{Example}

The effect of curvature ratio (R/a), on the variation of the non-dimensional frequency parameter with four-parameter power-law distribution FGM $(\mathrm{u}=1 / \mathrm{v}=0 / \mathrm{w}=0 / \varphi=5)$ and $\mathrm{FG}$ spherical shell made of SUS304/Si3N4, is described with SSSS CCCC, and HHHH boundary conditions.

In Tables IV-VI, respectively the frequency response shown in these three tables. For the above cases, five different values of curvature ratio $(\mathrm{R} / \mathrm{a}=5,10,20$ and 50,100) and Skew angle range from $0^{0}$ to $60^{\circ}$ are considered.

Tables IV and V show the frequencies for the first six modes for simply supported and clamped boundary conditions $(\mathrm{a} / \mathrm{h}=10, \mathrm{a} / \mathrm{b}=1)$, respectively.it is observed that the natural frequencies in all six modes increase with rising the skew angle. Whereas for shells with curvature ratio grows resultant shell stiffness change, the natural frequencies rates gradually dropped. Although the curvature ratio of any curved shell panel increases consistent approaches to the flatness.

Table VI. shows the non-dimensional frequency rate of the first six modes observed for accelerating trend $\mathrm{HHHH}$ boundary condition, with rising skew angle. Descent flow of non-dimensional frequency parameters while increasing curvature ratios.

\subsubsection{Example}

Tables VII to IX illustrate the effect of the aspect ratio on the frequency responses of the FG spherical shell panel has analyzed. for three different boundary conditions, and following geometric quantiles are five different values of aspect ratio $(a / b=1,1.5,2,2.5,3)$ and the $\mathrm{a} / \mathrm{h}=5, \mathrm{R} / \mathrm{a}=5$ and power-law distribution FGM $(u=1 / v=1 / w=2 / \varphi=2)$ with five skew angle $0^{0}, 15^{0}, 30^{\circ}, 45^{0}, 60^{\circ}$.

The detailed numerical results depicted in Table VII to IX. describe the variation of the fundamental natural frequencies with the power-law distribution, Skew angles for under different boundary conditions, the trend can be seen in numerical results that the non-dimensional frequencies rate slowly improves as the skew angle increases from $0^{0}$ to $30^{0}$.

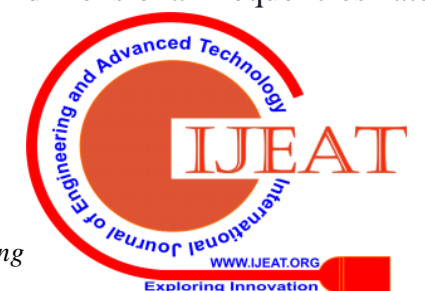


Pronounced frequency increments occurring when the skew angle rises from $30^{\circ}$ to $60^{\circ}$. The result shows that the frequency parameter values are increasing with the aspect ratio. Because the large aspect ratios are comparatively stiffer, and it also prominent affect the structural design and vibration behavior of the structure.

Tables VIII and IX. illustrate the first six frequency modes for Variation of Non-dimensional frequency parameter for clamped condition and hinged condition. The frequencies gradually increase as the aspect ratio increases. Between them CCCC boundary condition exhibit higher frequency parameter values compared to the other boundary condition.

\subsubsection{Example}

Tables X to XII demonstrates the effect of the thickness ratio on the frequency responses of the FG spherical shell SUS304/Si3N4 panel. With FGM $(u=1 / v=0 / w=2 / \varphi=2)$ the following geometric parameters $(\mathrm{a} / \mathrm{b}=1, \mathrm{R} / \mathrm{a}=5)$ and different thickness ratio values of $(\mathrm{a} / \mathrm{h}=5,10,20,50,100,200)$ are presented. Increase the skew angle from $0^{0}$ to $60^{\circ}$, the interval of $15^{0}$ under three different boundary conditions considered.

Table $\mathrm{X}$ shows the frequencies in the first six modes for simply supported with the power-law distribution. The frequency parameters are showing the enhancing type of behavior with the increasing thickness ratio and skew angle. The trends of nondimensional frequency response attributed gradually intensify the first mode to the sixth mode. When the calculations performed with skew angle $0^{0}$ to $60^{\circ}$.generally, the maximum frequency responses occurred at $60^{\circ}$. in which the without skew angle $0^{0}$ represents a rectangular spherical shell. The response of the frequency parameter for the skew angle with the thickness ratio increases the rate of stability for all the FGM skew structures.

Table XI and XII shows similar approach the effect of thickness ratio increases with skew angle and power law distribution parameters kept constant non dimensional frequency parameter responses shown for clamped and hinged boundary condition. Increment trends noticed at skew angle more than $30^{\circ}$.

Table-IV, V and VI: Variation of non-dimensional frequency responses with skew angle ( $\alpha$ ) for FG spherical shell (SUS304/Si3N4) panel for different curvature ratios(R/a).

Table-IV: (R/a) ratios under SSSS boundary condition

\begin{tabular}{|c|c|c|c|c|c|c|}
\hline $\mathrm{R} / \mathrm{a}$ & Mode & $0^{0}$ & $15^{0}$ & $30^{0}$ & $45^{0}$ & $60^{\circ}$ \\
\hline \multirow{6}{*}{5} & 1 & 8.1342 & 8.8455 & 11.1265 & 16.0583 & 28.2408 \\
\hline & 2 & 18.6354 & 18.5634 & 20.919 & 26.9614 & 42.1294 \\
\hline & 3 & 18.6371 & 21.2048 & 27.1647 & 33.3529 & 43.7535 \\
\hline & 4 & 25.4005 & 26.0718 & 28.4416 & 35.0249 & 48.2873 \\
\hline & 5 & 25.4039 & 26.2838 & 29.0977 & 38.1963 & 55.6096 \\
\hline & 6 & 28.329 & 28.751 & 31.2875 & 39.5096 & 56.2522 \\
\hline \multirow{6}{*}{10} & 1 & 7.852 & 8.5889 & 10.9303 & 15.9359 & 28.1964 \\
\hline & 2 & 18.54 & 18.4677 & 20.8429 & 26.9226 & 42.1646 \\
\hline & 3 & 18.5416 & 21.1294 & 27.1325 & 33.3257 & 43.704 \\
\hline & 4 & 25.3819 & 26.0521 & 28.4192 & 35.0052 & 48.2337 \\
\hline & 5 & 25.3853 & 26.2626 & 29.0588 & 38.188 & 55.7096 \\
\hline & 6 & 28.286 & 28.7097 & 31.2562 & 39.484 & 56.134 \\
\hline \multirow{6}{*}{20} & 1 & 7.7809 & 8.5248 & 10.8825 & 15.9081 & 28.1906 \\
\hline & 2 & 18.5194 & 18.447 & 20.8277 & 26.918 & 42.184 \\
\hline & 3 & 18.521 & 21.1142 & 27.1297 & 33.3126 & 43.6821 \\
\hline & 4 & 25.3726 & 26.0424 & 28.4084 & 34.9941 & 48.21 \\
\hline & 5 & 25.376 & 26.2524 & 29.0431 & 38.1929 & 55.7586 \\
\hline & 6 & 28.28 & 28.7043 & 31.2538 & 39.4836 & 56.0804 \\
\hline \multirow{6}{*}{50} & 1 & 7.7618 & 8.5078 & 10.8705 & 15.9022 & 28.1924 \\
\hline & 2 & 18.5157 & 18.4433 & 20.8259 & 26.9201 & 42.1961 \\
\hline & 3 & 18.5173 & 21.1124 & 27.1323 & 33.305 & 43.67 \\
\hline & 4 & 25.367 & 26.0366 & 28.4019 & 34.9871 & 48.1968 \\
\hline & 5 & 25.3704 & 26.2464 & 29.0349 & 38.1988 & 55.7858 \\
\hline & 6 & 28.2815 & 28.7059 & 31.2567 & 39.4873 & 56.0519 \\
\hline \multirow{6}{*}{100} & 1 & 7.7594 & 8.5058 & 10.8692 & 15.9021 & 28.1939 \\
\hline & 2 & 18.5159 & 18.4436 & 20.8265 & 26.9215 & 42.2002 \\
\hline & 3 & 18.5175 & 21.113 & 27.1339 & 33.3025 & 43.6661 \\
\hline & 4 & 25.3651 & 26.0347 & 28.3998 & 34.9847 & 48.1925 \\
\hline & 5 & 25.3686 & 26.2445 & 29.0324 & 38.2013 & 55.7941 \\
\hline & 6 & 28.2828 & 28.7073 & 31.2584 & 39.4892 & 56.0433 \\
\hline
\end{tabular}

Table-VI: (R/a) ratios under HHHH boundary condition

\begin{tabular}{|c|c|c|c|c|c|c|}
\hline R/a & Mode & $0^{0}$ & $15^{0}$ & $30^{0}$ & $45^{0}$ & $60^{0}$ \\
\hline \multirow{2}{*}{5} & 1 & 8.4725 & 9.1523 & 11.3585 & 16.2029 & 28.3116 \\
\cline { 2 - 7 } & 2 & 18.6498 & 18.5873 & 20.9517 & 27.0024 & 42.2158 \\
\hline
\end{tabular}

\begin{tabular}{|c|l|l|l|l|l|l|}
\hline $\mathrm{R} / \mathrm{a}$ & Mode & $0^{0}$ & $15^{0}$ & $30^{0}$ & $45^{0}$ & $60^{0}$ \\
\hline 5 & 1 & 13.7852 & 14.4958 & 17.0038 & 22.9074 & 37.7452 \\
\hline & 2 & 25.5709 & 25.3974 & 27.8927 & 34.6932 & 51.8779 \\
\hline & 3 & 25.5709 & 28.2801 & 34.5590 & 46.4707 & 66.0626 \\
\hline & 4 & 35.6781 & 36.1550 & 38.8760 & 47.6140 & 72.5375 \\
\hline & 5 & 42.6532 & 44.5548 & 50.3726 & 56.8799 & 77.5000 \\
\hline & 6 & 43.1177 & 46.3126 & 51.0773 & 59.7193 & 81.8035 \\
\hline 10 & 1 & 13.4253 & 14.1547 & 16.7163 & 22.6985 & 37.6241 \\
\hline & 2 & 25.5091 & 25.3276 & 27.8275 & 34.6463 & 51.8646 \\
\hline & 3 & 25.5091 & 28.2381 & 34.5472 & 46.4393 & 66.0542 \\
\hline & 4 & 35.6406 & 36.1137 & 38.8344 & 47.6463 & 72.4524 \\
\hline & 5 & 42.6497 & 44.5559 & 50.4235 & 56.8535 & 77.6167 \\
\hline & 6 & 43.0799 & 46.2858 & 51.0933 & 59.6466 & 81.7925 \\
\hline 20 & 1 & 13.3344 & 14.0689 & 16.6446 & 22.6473 & 37.5958 \\
\hline & 2 & 25.4983 & 25.3145 & 27.8159 & 34.6402 & 51.8695 \\
\hline & 3 & 25.4983 & 28.2329 & 34.5514 & 46.4377 & 66.0605 \\
\hline & 4 & 35.6369 & 36.1089 & 38.8297 & 47.6655 & 72.4136 \\
\hline & 5 & 42.6568 & 44.5645 & 50.4383 & 56.8378 & 77.6706 \\
\hline & 6 & 43.0762 & 46.2856 & 51.1071 & 59.6299 & 81.7971 \\
\hline 50 & 1 & 13.3094 & 14.0453 & 16.6251 & 22.6338 & 37.5892 \\
\hline & 2 & 25.4983 & 25.3137 & 27.8157 & 34.6421 & 51.8761 \\
\hline & 3 & 25.4983 & 28.2350 & 34.5572 & 46.4414 & 66.0676 \\
\hline & 4 & 35.6396 & 36.1112 & 38.8320 & 47.6780 & 72.3915 \\
\hline & 5 & 42.6638 & 44.5723 & 50.4424 & 56.8276 & 77.7015 \\
\hline & 6 & 43.0789 & 46.2896 & 51.1173 & 59.6262 & 81.8030 \\
\hline 100 & 1 & 13.3060 & 14.0422 & 16.6226 & 22.6322 & 37.5887 \\
\hline & 2 & 25.4994 & 25.3146 & 27.8167 & 34.6437 & 51.8789 \\
\hline & 3 & 25.4994 & 28.2365 & 34.5596 & 46.4434 & 66.0705 \\
\hline & 4 & 35.6413 & 36.1128 & 38.8336 & 47.6824 & 72.3844 \\
\hline & 5 & 42.6666 & 44.5753 & 50.4429 & 56.8240 & 77.7115 \\
\hline & 6 & 43.0806 & 46.2916 & 51.1210 & 59.6260 & 81.8056 \\
\hline & & & & & & \\
\hline & & & & & \\
\hline & & & & &
\end{tabular}

Table-VII: (a/b) ratios under SSSS boundary condition

\begin{tabular}{|r|l|l|l|l|l|l|}
\hline $\mathrm{a} / \mathrm{b}$ & Mode & $0^{0}$ & $15^{0}$ & $30^{0}$ & $45^{0}$ & $60^{0}$ \\
\hline 5 & 1 & 5.7832 & 6.1551 & 7.4093 & 10.1490 & 16.4495 \\
\hline & 2 & 10.2960 & 10.5675 & 11.5274 & 13.5194 & 17.7337 \\
\hline
\end{tabular}


Free Vibration Response of Four-Parameter Functionally Graded Thick Spherical Shell Formulation on Higher-Order Shear Deformation Theory

\begin{tabular}{|c|c|c|c|c|c|c|}
\hline & 3 & 18.6514 & 21.2125 & 27.1854 & 38.2220 & 55.9456 \\
\hline & 4 & 28.3367 & 28.7615 & 31.3040 & 39.4841 & 68.1196 \\
\hline & 5 & 34.8603 & 36.7765 & 43.2093 & 51.0223 & 69.4244 \\
\hline & 6 & 34.8888 & 38.1261 & 43.5059 & 54.9756 & 71.7047 \\
\hline \multirow{6}{*}{10} & 1 & 7.9025 & 8.6339 & 10.9621 & 15.9529 & 28.2036 \\
\hline & 2 & 18.5404 & 18.4693 & 20.8465 & 26.9288 & 42.1888 \\
\hline & 3 & 18.5420 & 21.1300 & 27.1396 & 38.1926 & 55.9460 \\
\hline & 4 & 28.2863 & 28.7103 & 31.2579 & 39.4785 & 68.1538 \\
\hline & 5 & 34.8334 & 36.7561 & 43.2031 & 51.0244 & 69.3626 \\
\hline & 6 & 34.8634 & 38.1083 & 43.4965 & 54.9021 & 71.7217 \\
\hline \multirow{6}{*}{20} & 1 & 7.7825 & 8.5262 & 10.8835 & 15.9093 & 28.1944 \\
\hline & 2 & 18.5205 & 18.4478 & 20.8286 & 26.9197 & 42.1931 \\
\hline & 3 & 18.5221 & 21.1161 & 27.1342 & 38.1968 & 55.9594 \\
\hline & 4 & 28.2842 & 28.7082 & 31.2574 & 39.4832 & 68.1664 \\
\hline & 5 & 34.8369 & 36.7576 & 43.2085 & 51.0342 & 69.3353 \\
\hline & 6 & 34.8635 & 38.1141 & 43.5028 & 54.8753 & 71.7419 \\
\hline \multirow{6}{*}{50} & 1 & 7.7673 & 8.5132 & 10.8761 & 15.9096 & 28.2032 \\
\hline & 2 & 18.5198 & 18.4470 & 20.8291 & 26.9231 & 42.2013 \\
\hline & 3 & 18.5213 & 21.1165 & 27.1367 & 38.2054 & 55.9717 \\
\hline & 4 & 28.2905 & 28.7145 & 31.2643 & 39.4884 & 68.1723 \\
\hline & 5 & 34.8444 & 36.7623 & 43.2145 & 51.0428 & 69.3204 \\
\hline & 6 & 34.8677 & 38.1222 & 43.5102 & 54.8625 & 71.7577 \\
\hline \multirow{6}{*}{100} & 1 & 7.7718 & 8.5175 & 10.8803 & 15.9141 & 28.2085 \\
\hline & 2 & 18.5214 & 18.4488 & 20.8312 & 26.9257 & 42.2049 \\
\hline & 3 & 18.5230 & 21.1181 & 27.1384 & 38.2093 & 55.9765 \\
\hline & 4 & 28.2938 & 28.7178 & 31.2678 & 39.4906 & 68.1741 \\
\hline & 5 & 34.8478 & 36.7644 & 43.2169 & 51.0462 & 69.3156 \\
\hline & 6 & 34.8697 & 38.1257 & 43.5132 & 54.8588 & 71.7635 \\
\hline
\end{tabular}

\begin{tabular}{|l|l|l|l|l|l|l|}
\hline & 3 & 10.2974 & 10.6524 & 11.7823 & 14.1991 & 19.5705 \\
\hline & 4 & 12.4627 & 12.3156 & 13.4380 & 16.4416 & 22.7025 \\
\hline & 5 & 12.4637 & 13.8485 & 15.9620 & 18.1586 & 23.5558 \\
\hline & 6 & 14.6075 & 14.9162 & 16.9025 & 22.1652 & 29.7113 \\
\hline 10 & 1 & 8.7493 & 9.2233 & 10.8367 & 13.0822 & 16.1514 \\
\hline & 2 & 10.3129 & 10.5758 & 11.4255 & 14.4034 & 22.7390 \\
\hline & 3 & 14.8484 & 15.3831 & 17.1976 & 20.9389 & 28.4447 \\
\hline & 4 & 15.4680 & 15.9442 & 17.5393 & 21.1489 & 28.5110 \\
\hline & 5 & 18.6116 & 18.9673 & 20.1997 & 22.8512 & 30.0434 \\
\hline & 6 & 20.6398 & 21.1333 & 22.7244 & 25.9653 & 32.8987 \\
\hline 20 & 1 & 10.3194 & 10.5320 & 11.2000 & 12.4246 & 14.4644 \\
\hline & 2 & 12.4448 & 13.0797 & 15.2538 & 20.0984 & 28.7650 \\
\hline & 3 & 17.9209 & 18.5898 & 20.8499 & 24.2538 & 31.4612 \\
\hline & 4 & 20.6370 & 20.9460 & 21.9990 & 25.7646 & 36.9860 \\
\hline & 5 & 20.6530 & 21.2952 & 23.5075 & 28.2407 & 38.2955 \\
\hline & 6 & 23.0793 & 23.7602 & 25.9268 & 30.3184 & 39.7546 \\
\hline 50 & 1 & 10.3226 & 10.4999 & 11.0476 & 12.0192 & 13.5621 \\
\hline & 2 & 16.6249 & 17.4449 & 20.2535 & 23.8835 & 27.4354 \\
\hline & 3 & 20.6595 & 20.9632 & 21.9543 & 26.5005 & 41.0208 \\
\hline & 4 & 21.5121 & 22.3313 & 25.1120 & 31.2112 & 41.6013 \\
\hline & 5 & 25.8039 & 26.6442 & 29.4697 & 34.9583 & 45.2808 \\
\hline & 6 & 27.7910 & 28.5880 & 31.2314 & 35.7258 & 48.8631 \\
\hline 100 & 1 & 10.3244 & 10.4767 & 10.9425 & 11.7546 & 13.0166 \\
\hline & 2 & 20.6632 & 20.9428 & 21.8322 & 23.4993 & 26.4443 \\
\hline & 3 & 21.1191 & 22.1321 & 25.5951 & 33.2566 & 40.9791 \\
\hline & 4 & 25.4832 & 26.4711 & 29.8332 & 35.2322 & 50.5276 \\
\hline & 5 & 30.9693 & 31.4171 & 32.6128 & 37.2392 & 50.9167 \\
\hline & 6 & 31.0842 & 31.9940 & 35.4394 & 42.8158 & 54.3551 \\
\hline
\end{tabular}

Table-VII, VIII and IX: Variation of non-dimensional frequency responses with skew angle ( $\alpha$ ) for FG spherical shell (SUS304/Si3N4) panel for different aspect ratios(a/b).

\begin{tabular}{|c|c|c|c|c|c|c|}
\hline \multicolumn{7}{|c|}{$\begin{array}{l}\text { Table-VIII: (a/b) ratios under CCCC boundary } \\
\text { condition }\end{array}$} \\
\hline$a / b$ & Mode & $0^{0}$ & $15^{0}$ & $30^{\circ}$ & $45^{0}$ & $60^{\circ}$ \\
\hline \multirow{6}{*}{5} & 1 & 8.8081 & 9.2064 & 10.5665 & 13.5559 & 20.3344 \\
\hline & 2 & 15.1719 & 15.0371 & 16.1793 & 19.2491 & 26.5813 \\
\hline & 3 & 15.1719 & 16.5252 & 19.4987 & 23.1289 & 29.4766 \\
\hline & 4 & 19.9190 & 19.6581 & 20.5361 & 24.8215 & 32.8185 \\
\hline & 5 & 19.9190 & 20.5161 & 21.6284 & 25.3180 & 37.8290 \\
\hline & 6 & 20.3675 & 21.2588 & 24.0197 & 29.2839 & 39.4421 \\
\hline \multirow{6}{*}{10} & 1 & 12.7704 & 13.3237 & 15.2007 & 19.2854 & 28.4888 \\
\hline & 2 & 17.9687 & 18.5113 & 20.3743 & 24.4824 & 33.8373 \\
\hline & 3 & 22.9911 & 23.4205 & 24.9741 & 28.5828 & 37.0965 \\
\hline & 4 & 24.0548 & 25.1109 & 27.3669 & 31.4131 & 41.2999 \\
\hline & 5 & 25.5670 & 25.8417 & 28.6288 & 35.9897 & 48.6611 \\
\hline & 6 & 27.6275 & 28.6193 & 31.8757 & 38.6576 & 49.0154 \\
\hline \multirow{6}{*}{20} & 1 & 17.4387 & 18.1694 & 20.6443 & 26.0239 & 38.1852 \\
\hline & 2 & 21.6496 & 22.3581 & 24.7632 & 30.0128 & 41.9662 \\
\hline & 3 & 26.7273 & 27.3531 & 29.5185 & 34.3773 & 45.7153 \\
\hline & 4 & 28.3553 & 29.0063 & 31.2859 & 36.4409 & 48.5104 \\
\hline & 5 & 33.2734 & 34.5870 & 38.5906 & 44.2202 & 56.1039 \\
\hline & 6 & 35.8010 & 37.0181 & 39.8496 & 45.5064 & 57.0656 \\
\hline \multirow{6}{*}{50} & 1 & 22.3722 & 23.2845 & 26.3739 & 33.0956 & 48.3317 \\
\hline & 2 & 25.8568 & 26.7354 & 29.7175 & 36.2373 & 51.1426 \\
\hline & 3 & 30.8821 & 31.6926 & 34.4757 & 40.6673 & 55.0277 \\
\hline & 4 & 31.7374 & 32.5695 & 35.4204 & 41.7420 & 56.4424 \\
\hline & 5 & 39.5202 & 40.2735 & 42.9838 & 49.2693 & 63.8587 \\
\hline & 6 & 42.4532 & 43.0424 & 45.3010 & 50.7194 & 64.3654 \\
\hline \multirow{6}{*}{100} & 1 & 27.4183 & 28.5139 & 32.2258 & 40.3106 & 58.6562 \\
\hline & 2 & 30.3728 & 31.4296 & 35.0188 & 42.8773 & 60.8623 \\
\hline & 3 & 35.3061 & 36.3030 & 39.7150 & 47.2690 & 64.6982 \\
\hline & 4 & 35.5511 & 36.5563 & 39.9883 & 47.5752 & 65.1883 \\
\hline & 5 & 42.6764 & 43.6347 & 46.9519 & 54.4237 & 72.1211 \\
\hline & 6 & 45.8049 & 46.6176 & 49.5032 & 56.1805 & 72.2195 \\
\hline
\end{tabular}

Table-IX: (a/b) ratios under HHHH boundary

\begin{tabular}{|r|l|l|l|l|l|l|}
\multicolumn{7}{|c|}{ Table-IX: (a/b) ratios under HHHH boundary } \\
\hline $\mathrm{a} / \mathrm{b}$ & Mode & $0^{0}$ & $15^{0}$ & $30^{0}$ & $45^{0}$ & $60^{0}$ \\
\hline 5 & 1 & 5.9072 & 6.2717 & 7.5068 & 10.2225 & 16.5003 \\
\hline & 2 & 12.4582 & 12.3155 & 13.4385 & 16.4407 & 23.5516 \\
\hline & 3 & 12.4592 & 13.8363 & 16.8789 & 21.4710 & 27.0510 \\
\hline & 4 & 17.9300 & 18.0399 & 19.0909 & 22.1785 & 29.8667 \\
\hline & 5 & 18.4713 & 18.2926 & 19.1250 & 22.8874 & 34.8976 \\
\hline & 6 & 18.4714 & 19.5931 & 21.9185 & 26.2786 & 36.2695 \\
\hline 10 & 1 & 8.8343 & 9.3043 & 10.9069 & 14.4586 & 22.7780 \\
\hline & 2 & 14.8595 & 15.3941 & 17.2089 & 21.1565 & 30.0536 \\
\hline & 3 & 21.0959 & 22.0483 & 23.5298 & 26.9530 & 35.0236 \\
\hline & 4 & 21.6577 & 22.1776 & 24.8005 & 28.7235 & 38.2320 \\
\hline & 5 & 23.1498 & 23.3571 & 25.7373 & 32.2356 & 41.9301 \\
\hline & 6 & 24.3454 & 25.1272 & 27.6398 & 33.6465 & 43.7713 \\
\hline 20 & 1 & 12.5078 & 13.1401 & 15.3069 & 20.1412 & 31.4891 \\
\hline & 2 & 17.9394 & 18.6082 & 20.8683 & 25.7830 & 37.0051 \\
\hline & 3 & 25.5191 & 26.1277 & 28.2378 & 32.9834 & 44.0814 \\
\hline & 4 & 25.6167 & 26.2474 & 28.4495 & 33.3947 & 44.8479 \\
\hline & 5 & 29.6972 & 30.6271 & 33.4890 & 39.0482 & 49.4467 \\
\hline & 6 & 30.9413 & 32.2413 & 36.2565 & 41.3063 & 50.9772 \\
\hline 50 & 1 & 16.6747 & 17.4928 & 20.2963 & 26.5338 & 41.0442 \\
\hline & 2 & 21.5333 & 22.3523 & 25.1325 & 31.2312 & 45.2959 \\
\hline & 3 & 28.5877 & 29.3856 & 32.1067 & 38.1001 & 50.6459 \\
\hline & 4 & 29.7861 & 30.5863 & 33.3363 & 39.4611 & 51.9090 \\
\hline & 5 & 35.1859 & 36.1327 & 39.1974 & 45.2062 & 53.6732 \\
\hline & 6 & 37.1813 & 37.8976 & 40.4914 & 46.4918 & 55.8732 \\
\hline 100 & 1 & 21.1603 & 22.1716 & 25.6301 & 33.2848 & 50.5074 \\
\hline & 2 & 25.5048 & 26.4925 & 29.8540 & 37.2561 & 50.9363 \\
\hline & 3 & 31.9658 & 32.9208 & 36.1718 & 43.3341 & 54.3695 \\
\hline & 4 & 34.3046 & 35.2955 & 38.6883 & 46.2018 & 55.2704 \\
\hline & 5 & 40.0165 & 40.9343 & 44.1032 & 49.9764 & 60.0647 \\
\hline & 6 & 40.0737 & 41.0880 & 44.3515 & 50.8968 & 61.3982 \\
\hline & & & & & & \\
\hline & & & & \\
\hline & & & & \\
\hline & & &
\end{tabular}


Table-X, XI and XII: Variation of non-dimensional frequency responses with skew angle ( $\alpha$ ) for FG spherical shell (SUS304/Si3N4) panel for different thickness ratios(a/h).

Table-X:(a/h) ratios under SSSS boundary condition

\begin{tabular}{|c|c|c|c|c|c|c|}
\hline $\mathrm{a} / \mathrm{h}$ & Mode & $0^{0}$ & $15^{0}$ & $30^{0}$ & $45^{0}$ & $60^{0}$ \\
\hline \multirow{6}{*}{5} & 1 & 6.4517 & 6.8699 & 8.2806 & 11.3646 & 18.4674 \\
\hline & 2 & 11.6504 & 11.9565 & 13.0387 & 15.2824 & 20.0147 \\
\hline & 3 & 11.6520 & 12.0521 & 13.3247 & 16.0424 & 22.0580 \\
\hline & 4 & 13.9565 & 13.7928 & 15.0633 & 18.4601 & 25.5604 \\
\hline & 5 & 13.9576 & 15.5193 & 18.0279 & 20.4892 & 26.5075 \\
\hline & 6 & 16.5076 & 16.8543 & 18.9669 & 24.9091 & 33.2308 \\
\hline \multirow{6}{*}{10} & 1 & 7.3587 & 8.0082 & 10.0863 & 14.5776 & 25.7048 \\
\hline & 2 & 16.8844 & 16.8245 & 18.9806 & 24.5054 & 38.4166 \\
\hline & 3 & 16.8859 & 19.2291 & 24.6798 & 30.5808 & 40.1139 \\
\hline & 4 & 23.2894 & 23.9049 & 26.0777 & 32.1123 & 44.2728 \\
\hline & 5 & 23.2926 & 24.0993 & 26.6772 & 34.7869 & 50.8794 \\
\hline & 6 & 25.7174 & 26.1095 & 28.4429 & 35.9860 & 51.5037 \\
\hline \multirow{6}{*}{20} & 1 & 8.6163 & 9.6496 & 12.3159 & 17.7039 & 31.9963 \\
\hline & 2 & 18.5522 & 18.9439 & 22.0618 & 29.3192 & 48.7200 \\
\hline & 3 & 18.5535 & 21.8058 & 29.3455 & 43.4518 & 68.7196 \\
\hline & 4 & 28.6498 & 29.7997 & 33.8983 & 44.5543 & 80.1802 \\
\hline & 5 & 36.3118 & 38.8862 & 47.4876 & 60.5394 & 82.5620 \\
\hline & 6 & 36.3335 & 40.8847 & 48.7292 & 61.2053 & 88.6178 \\
\hline \multirow{6}{*}{50} & 1 & 13.9863 & 15.6158 & 18.0300 & 23.4077 & 40.2479 \\
\hline & 2 & 22.0573 & 23.5621 & 27.2538 & 35.9980 & 61.7974 \\
\hline & 3 & 22.0593 & 27.8375 & 37.0190 & 55.2876 & 94.6650 \\
\hline & 4 & 31.7649 & 35.5501 & 41.8746 & 55.6843 & 105.5847 \\
\hline & 5 & 40.4874 & 44.1676 & 55.8575 & 81.8853 & 138.3160 \\
\hline & 6 & 40.5048 & 50.8533 & 61.1467 & 82.4093 & 153.6224 \\
\hline \multirow{6}{*}{100} & 1 & 25.0060 & 26.4585 & 28.0029 & 32.2984 & 48.5788 \\
\hline & 2 & 30.3975 & 32.1713 & 35.1455 & 43.4712 & 72.0867 \\
\hline & 3 & 30.4025 & 37.3366 & 44.9454 & 63.1893 & 113.6363 \\
\hline & 4 & 38.1385 & 43.7978 & 49.4988 & 64.8212 & 119.2980 \\
\hline & 5 & 46.1670 & 50.4299 & 62.4724 & 91.5951 & 173.9507 \\
\hline & 6 & 46.2108 & 60.4894 & 70.1668 & 96.1937 & 176.2264 \\
\hline \multirow{6}{*}{200} & 1 & 48.4058 & 49.3974 & 50.3769 & 53.3064 & 65.8688 \\
\hline & 2 & 51.5289 & 52.8462 & 54.7069 & 60.7414 & 86.1456 \\
\hline & 3 & 51.5408 & 56.9300 & 62.0211 & 77.0992 & 129.1362 \\
\hline & 4 & 56.4229 & 61.5382 & 65.6368 & 79.0476 & 131.7246 \\
\hline & 5 & 62.4662 & 66.2262 & 76.1777 & 103.2203 & 191.4092 \\
\hline & 6 & 62.5921 & 75.3887 & 83.7672 & 109.7436 & 197.5931 \\
\hline
\end{tabular}

Table-XII:(a/h) ratios under HHHH boundary condition

\begin{tabular}{|c|c|c|c|c|c|c|}
\hline $\mathrm{a} / \mathrm{h}$ & Mode & 0 & 150 & 300 & 450 & 600 \\
\hline \multirow[b]{6}{*}{5} & 1 & 6.5043 & 6.9184 & 8.3188 & 11.3914 & 18.4895 \\
\hline & 2 & 13.9562 & 13.7929 & 15.0597 & 18.4501 & 26.485 \\
\hline & 3 & 13.9574 & 15.5164 & 18.9606 & 24.1052 & 30.2169 \\
\hline & 4 & 20.1151 & 20.2391 & 21.4272 & 24.9177 & 33.6033 \\
\hline & 5 & 20.7755 & 20.5796 & 21.5076 & 25.7742 & 38.5514 \\
\hline & 6 & 20.7755 & 22.0166 & 24.578 & 29.3184 & 40.7274 \\
\hline \multirow[b]{6}{*}{10} & 1 & 7.6274 & 8.2508 & 10.2663 & 14.6839 & 25.75 \\
\hline & 2 & 16.8923 & 16.8397 & 19.0029 & 24.5347 & 38.4816 \\
\hline & 3 & 16.8937 & 19.2333 & 24.697 & 34.8032 & 51.1046 \\
\hline & 4 & 25.7194 & 26.1136 & 28.4516 & 35.9653 & 62.2911 \\
\hline & 5 & 31.6884 & 33.4479 & 39.3525 & 46.5531 & 63.6993 \\
\hline & 6 & 31.7164 & 34.6827 & 39.6279 & 50.4194 & 65.62 \\
\hline \multirow[b]{6}{*}{20} & 1 & 9.8126 & 10.715 & 13.1239 & 18.2154 & 32.2128 \\
\hline & 2 & 18.6299 & 19.0468 & 22.1707 & 29.4154 & 48.7839 \\
\hline & 3 & 18.6309 & 21.8534 & 29.375 & 43.4947 & 68.751 \\
\hline & 4 & 28.6833 & 29.8391 & 33.9445 & 44.5793 & 82.6698 \\
\hline & 5 & 36.3233 & 38.8906 & 47.4931 & 60.622 & 93.1407 \\
\hline & 6 & 36.3377 & 40.8951 & 48.7465 & 66.8741 & 115.9704 \\
\hline \multirow[b]{5}{*}{50} & 1 & 19.0081 & 20.0154 & 21.7918 & 26.313 & 41.8617 \\
\hline & 2 & 22.7683 & 24.2892 & 27.9856 & 36.6878 & 62.2776 \\
\hline & 3 & 22.7685 & 28.3149 & 37.3185 & 55.456 & 94.888 \\
\hline & 4 & 32.2559 & 36.0186 & 42.3101 & 56.0477 & 105.6741 \\
\hline & 5 & 40.6212 & 44.3109 & 55.9463 & 82.0314 & 138.406 \\
\hline
\end{tabular}

Table-XI:(a/h) ratios under CCCC boundary condition

\begin{tabular}{|c|c|c|c|c|c|c|}
\hline $\mathrm{a} / \mathrm{h}$ & Mode & $0^{0}$ & $15^{0}$ & $30^{0}$ & $45^{0}$ & $60^{\circ}$ \\
\hline \multirow{6}{*}{5} & 1 & 9.8794 & 10.3289 & 11.8646 & 15.2442 & 22.9182 \\
\hline & 2 & 17.0054 & 16.8584 & 18.1480 & 21.6055 & 29.8225 \\
\hline & 3 & 17.0054 & 18.5208 & 21.8475 & 26.1381 & 33.2650 \\
\hline & 4 & 22.5459 & 22.2448 & 23.2275 & 27.9311 & 36.9571 \\
\hline & 5 & 22.5459 & 23.0560 & 24.3189 & 28.3150 & 41.8291 \\
\hline & 6 & 22.8831 & 24.0663 & 27.1979 & 33.1954 & 44.4823 \\
\hline \multirow{6}{*}{10} & 1 & 12.4969 & 13.1428 & 15.4252 & 20.8108 & 34.4046 \\
\hline & 2 & 23.2365 & 23.0804 & 25.3660 & 31.6018 & 47.4040 \\
\hline & 3 & 23.2365 & 25.7121 & 31.4611 & 42.4077 & 60.4605 \\
\hline & 4 & 32.4781 & 32.9189 & 35.4217 & 43.4496 & 66.5092 \\
\hline & 5 & 38.8871 & 40.6343 & 46.1443 & 52.1455 & 71.0082 \\
\hline & 6 & 39.3024 & 42.2337 & 46.6325 & 54.5972 & 74.9676 \\
\hline \multirow{6}{*}{20} & 1 & 14.7733 & 15.4882 & 18.0953 & 24.6611 & 43.2079 \\
\hline & 2 & 27.3522 & 27.2829 & 30.4831 & 39.4002 & 63.8952 \\
\hline & 3 & 27.3522 & 30.4735 & 38.1045 & 55.1545 & 86.1917 \\
\hline & 4 & 39.2357 & 40.1434 & 44.2924 & 55.5490 & 99.1637 \\
\hline & 5 & 49.0480 & 51.6557 & 60.7964 & 75.1619 & 112.5701 \\
\hline & 6 & 49.4081 & 53.3924 & 61.7315 & 82.1526 & 133.1525 \\
\hline \multirow{6}{*}{50} & 1 & 21.6519 & 22.2498 & 24.5787 & 31.1803 & 52.6386 \\
\hline & 2 & 32.1869 & 32.4095 & 36.6455 & 48.6762 & 83.6657 \\
\hline & 3 & 32.1869 & 35.5488 & 44.4434 & 65.6432 & 123.1431 \\
\hline & 4 & 45.3456 & 47.1128 & 54.1330 & 72.5531 & 125.0019 \\
\hline & 5 & 58.6460 & 62.2989 & 75.3989 & 105.7419 & 175.1750 \\
\hline & 6 & 59.1405 & 63.9297 & 79.6030 & 107.1998 & 192.3387 \\
\hline \multirow{6}{*}{100} & 1 & 35.8385 & 36.2717 & 38.0129 & 43.3448 & 63.6282 \\
\hline & 2 & 39.8495 & 40.3595 & 44.7236 & 57.5701 & 98.5983 \\
\hline & 3 & 39.8495 & 42.6585 & 51.0047 & 72.8823 & 139.4303 \\
\hline & 4 & 51.7569 & 53.8672 & 62.0961 & 84.5981 & 151.6135 \\
\hline & 5 & 65.0468 & 68.9822 & 83.5305 & 120.8450 & 228.1453 \\
\hline & 6 & 66.3525 & 71.1334 & 88.5242 & 126.4352 & 228.7171 \\
\hline \multirow{6}{*}{200} & 1 & 60.2444 & 61.2051 & 65.1993 & 72.2223 & 88.1821 \\
\hline & 2 & 60.2444 & 61.7507 & 67.3210 & 76.5853 & 116.4895 \\
\hline & 3 & 64.4821 & 65.0573 & 67.6684 & 86.0960 & 151.9361 \\
\hline & 4 & 68.9093 & 71.2773 & 79.1972 & 100.7317 & 173.5670 \\
\hline & 5 & 79.0675 & 82.5304 & 95.8739 & 132.7832 & 249.6854 \\
\hline & 6 & 85.1334 & 88.4739 & 102.6578 & 142.6604 & 265.1871 \\
\hline
\end{tabular}

\begin{tabular}{|c|c|c|c|c|c|c|} 
& 6 & 40.7725 & 51.0893 & 61.3167 & 82.4648 & 153.6792 \\
\hline \multirow{6}{*}{1} & 32.7629 & 34.3303 & 37.1176 & 40.5725 & 54.3817 \\
\cline { 2 - 7 } & 2 & 32.763 & 35.9367 & 37.5206 & 46.0223 & 74.1566 \\
\cline { 2 - 7 } & 3 & 35.5695 & 38.9013 & 46.0622 & 63.8692 & 114.6493 \\
\cline { 2 - 7 } & 4 & 40.2672 & 45.6218 & 51.2829 & 66.3641 & 119.6135 \\
\cline { 2 - 7 } & 5 & 46.8356 & 51.3067 & 63.0039 & 91.8995 & 174.3796 \\
\cline { 2 - 7 } & 6 & 48.277 & 61.2964 & 70.9567 & 96.8843 & 176.3885 \\
\hline & 1 & 57.0694 & 57.8103 & 60.4599 & 68.0053 & 82.6111 \\
\cline { 2 - 7 } & 2 & 57.0695 & 60.8844 & 65.4804 & 71.4613 & 93.7315 \\
\cline { 2 - 7 } & 3 & 60.1267 & 62.3732 & 65.6316 & 79.5537 & 132.8953 \\
\cline { 2 - 7 } & 4 & 62.6182 & 67.3913 & 73.5671 & 85.3047 & 133.4042 \\
\cline { 2 - 7 } 200 & 5 & 64.7978 & 72.0147 & 78.9201 & 104.6425 & 192.0976 \\
\cline { 2 - 7 } & 6 & 73.2334 & 78.3517 & 86.9426 & 112.7345 & 199.6014 \\
\hline
\end{tabular}

HSDT conjunction with the finite element method. The comparison studies divulge the accuracy of the current model, and good agreement observed those available in the literature. The results computed via MATLAB environment.to show the robustness of the formulation explores different sets of geometrical parameters of the shell curvature ratio, aspect ratio, and thickness ratio, and choice of material distribution parameters, and skew angles under various boundary conditions considered here.

Published By: 
Based on the parametric study, numerical results revealed by using the four-parameter Power-law distribution on rectangular spherical shell and influence of $\mathrm{u}, \mathrm{v}$, and $\mathrm{w}$ parameters on the non-dimensional frequency responses examined. The following important conclusion from this study is summarized.

- The frequency responses are decreasing trend as the curvature ratio increases.

- The frequency responses are gradually rising as the thickness ratio and aspect ratio increases.

- In all cases, the boundary conditions have a perceptible effect on the frequency parameter of the spherical shell. The frequency parameters are higher for all the FG shell clamped boundary conditions.

- Variation of frequency parameter with a different power-law exponent $(\varphi)$ and material parameters $(\mathrm{u}, \mathrm{v}$, and $\mathrm{w}$ ) It is possible to approach to change the behavior of the structure.

- The influence of skewangles the non-dimensional frequency parameters exhibit 00 for minimum at 600 maximum response. all the frequency parameter values are escalating with skewangles.

- The frequency responses are maximum and minimum for the spherical shells.

\section{SUMMARY AND CONCLUSIONS}

In this study, free vibration responses of FGM spherical shell (SUS304/(Si3N4) rectangular form observed and presented. The FGM material composition, material properties vary continuously from metal (top/bottom surface) to ceramic (base/top surface). Employed Voigt's micromechanical model achieved through the four-parameter power-law distribution of the volume fractions. Convergence and comparison tests performed to illustrate the stability and exactness of the present mathematical model governed by

\section{REFERENCES}

1. C. T. Loy, K. Y. Lam, and J. N. Reddy, "Vibration of functionally graded cylindrical shells," Int. J. Mech. Sci., vol. 41, no. 3, pp. 309-324, 1999.

2. S. C. Pradhan, C. T. Loy, K. Y. Lam, and J. N. Reddy, "Vibration characteristics of functionally graded cylindrical shells under various boundary conditions," vol. 61, pp. 111-129, 2000.

3. J.N.Reddy, "Analysis of functionally graded plates," Int. J. Numer. Methods Eng., vol. 47, no. June 1999, pp. 663-684, 2000. 4.T. Y. Ng, K. Y. Lam, K. M. Liew, and J. N. Reddy, "Dynamic stability analysis of functionally graded cylindrical shells under periodic axial loading," Int. J. Solids Struct., vol. 38, no. 8, pp. 1295-1309, 2001.

5. K. M. Liew, L. X. Peng, and T. Y. Ng, "Three-dimensional vibration analysis of spherical shell panels subjected to different boundary conditions," vol. 44, pp. 2103-2117, 2002.

6. J. N. Reddy and Z. Cheng, "Frequency correspondence between membranes and functionally graded spherical shallow shells of polygonal planform," vol. 44, pp. 967-985, 2002.

7. X. X. Hu, T. Sakiyama, H. Matsuda, and C. Morita, "Vibration analysis of rotating twisted and open conical shells," Int. J. Solids Struct., vol. 39, no. 25, pp. 6121-6134, 2002.

8. E. Artioli and E. Viola, "Free vibration analysis of spherical caps using a G.D.Q. numerical solution," J. Press. Vessel Technol. Trans. ASME, vol. 128, no. 3, pp. 370-378, 2006.

9. R. A. Arciniega and J. N. Reddy, "Large deformation analysis of functionally graded shells," Int. J. Solids Struct., vol. 44, no. 6, pp. 2036-2052, 2007.

10. X. Zhao, Y. Y. Lee, and K. M. Liew, "Free vibration analysis of functionally graded plates using the element-free kp-Ritz method," $J$. Sound Vib., vol. 319, no. 3-5, pp. 918-939, 2009.

11. F. Tornabene and E. Viola, "Vibration analysis of spherical structural elements using the GDQ method," Comput. Math. with Appl., vol. 53, no. 10, pp. 1538-1560, 2007.

12. F. Tornabene and E. Viola, "2-D solution for free vibrations of parabolic shells using generalized differential quadrature method," Eur. J. Mech. A/Solids, vol. 27, no. 6, pp. 1001-1025, 2008.

13. F. Tornabene, "Free vibration analysis of functionally graded conical, cylindrical shell and annular plate structures with a four-paramete power-law distribution," Comput. Methods Appl. Mech. Eng., vol. 198, no. 37-40, pp. 2911-2935, 2009.

14. E. Viola and F. Tornabene, "Free vibrations of three parameter functionally graded parabolic panels of revolution," Mech. Res. Commun., vol. 36, no. 5, pp. 587-594, 2009.

15. F. Tornabene and E. Viola, Free vibrations of four-parameter functionally graded parabolic panels and shells of revolution, vol. 28, no. 5. 2009.

16. F. Tornabene and A. Ceruti, "Mixed static and dynamic optimization of four-parameter functionally graded completely doubly curved and degenerate shells and panels using GDQ method," Math. Probl. Eng., vol. 2013, 2013

17. M. H. Yas and B. Sobhani Aragh, "Three-dimensional analysis for thermoelastic response of functionally graded fiber reinforced cylindrical panel," Compos. Struct., vol. 92, no. 10, pp. 2391-2399, 2010.

18. M. Amabili and J. N. Reddy, "A new non-linear higher-order shear deformation theory for large-amplitude vibrations of laminated doubly curved shells," Int. J. Non. Linear. Mech., vol. 45, no. 4, pp. 409-418, 2010 .

19. M. Talha and B. N. Singh, "Static response and free vibration analysis of FGM plates using higher order shear deformation theory," Appl. Math. Model., vol. 34, no. 12, pp. 3991-4011, 2010.

20. H. Shen and Z. Wang, "Assessment of Voigt and Mori - Tanaka models for vibration analysis of functionally graded plates," Compos. Struct. vol. 94, no. 7, pp. 2197-2208, 2012.

21. A. M. A. Neves et al., "Free vibration analysis of functionally graded shells by a higher-order shear deformation theory and radial basis functions collocation, accounting for through-the-thickness deformations," Eur. J. Mech. A/Solids, vol. 37, pp. 24-34, 2013.

22. S. K. P. Vishesh Ranjan Kar, "Free vibration responses of temperature dependent functionally graded curved panels under thermal environment," pp. 2006-2024, 2015.

23. A. Kumar, A. Chakrabarti, and P. Bhargava, "Vibration analysis of laminated composite skew cylindrical shells using higher order shear deformation theory," JVC/Journal Vib. Control, vol. 21, no. 4, pp. 725-735, 2015

24. C. Zhang, G. Jin, X. Ma, and T. Ye, "Vibration analysis of circular cylindrical double-shell structures under general coupling and end boundary conditions," Appl. Acoust., vol. 110, pp. 176-193, 2016.

25. D. Punera and T. Kant, "Free vibration of functionally graded open cylindrical shells based on several refined higher order displacement models," Thin-Walled Struct., vol. 119, 2017.

26. C. M. Badiganti and R. Koona, "Harmonic frequency analysis of skewed functionally graded flat and spherical shallow shells," Results Phys., vol 10, no. June, pp. 987-992, 2018.

27. B. C. Mouli, V. R. Kar, K. Ramji, and M. Rajesh, "Free vibration of functionally graded conical shell," Mater. Today Proc., vol. 5, no. 6, pp. 14302-14308,

2018. 28. B. C. Mouli, K. Ramji, V. R. Kar,subrata k panda,lalepalli Anil k and harsh $\mathrm{k}$ pandey "Numerial sudy of temperature dependent eigen frequency response of tilted functionally graded shell structures," structural engineering and mechanics., vol. 68, no. 5, pp. 527-536, 2018.

29. Cook, R. D. Malkus, D. S. Plesha, M. E., Witt, R. J., (2009). Concepts and applications of finite element analysis. John Wiley \& Sons (Singapore).

30. Pandya, B.N., Kant, T. (1988a). Higher-order shear deformable theories for flexure of sandwich plates-Finite element evaluations. International Journal of Solids and Structures 24(12): 1267-1286.

31. Pandya, B.N., Kant, T. (1988b). Finite element analysis of laminated composite plates using a Higher-order displacement model. Composite Science and Technology 32: 137-155.

Published By: 


\section{AUTHORS PROFILE}

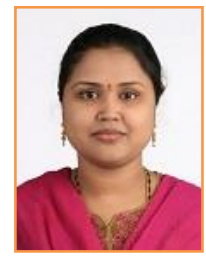

Raparthi Srilakshmi, Research Scholar in the Department of Mechanical Engineering, Andhra University has published paper on conditon monitoring. She has Diploma in Polytechnic, BE Mechanical, and M.Tech in Machine Design. She is interested in the areas of FEA, Composites, Solid Mechanics, Vibration Analysis, Signal Analysis, Condition Monitoring and SHM.

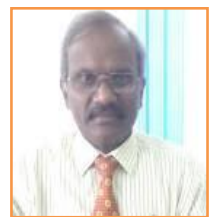

Prof. Ch. Ratnam, Professor and Head of the Department in the Department of Mechanical Engineering, Andhra University. He has books published on Fluid Mechanics \& Machinery and Geometrical Drawing. He also received an award for best paper published in IEI Journal for the year 2003-2004 and has over 60 papers in National and International journals. He has ample knowledge in Mechanical Engineering and Science, Vibration and Structural Health Monitoring, Engineering Optimization, Finite Element Analysis, Computer Aided Design and Design of Engineering.

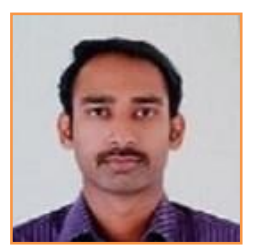

Chandra Mouli Badiganti, Assoc. Professor in the Department of Mechanical Engineering of RISE Krishna Sai Prakasam Group of Institution has published around 11 papers in various reputed journals. He has teaching experience in Strength of Materials, Composites,Engineering Drawing, Production Engineering. 